\title{
HUBUNGAN ANTARA KARAKTERISTIK DENGAN PERSEPSI PETERNAK TERHADAP INSEMINASI BUATAN PADA SAPI POTONG KELURAHAN TUAN-TUAN KECAMATAN BENUA KAYONG KABUPATEN KETAPANG
}

\author{
Khairul Umam ${ }^{1)}$, Novira Kusrini ${ }^{2)}$, Dewi Kurniati ${ }^{2)}$ \\ 1) Mahasiswa Fakultas Pertanian Universitas Tanjungpura Pontianak \\ 2) Dosen Fakultas Pertanian Universitas Tanjungpura Pontianak
}

\begin{abstract}
Abstrak
Hubungan Antara Karakteristik dengan Persepsi Peternak Terhadap Inseminasi Buatan pada Sapi Potong di Kelurahan Tuan-Tuan Kecamatan Benua Kayong Kabupaten Ketapang, di bawah bimbingan Dr. Novira Kusrini, SP, M.Si dan Dewi Kurniati, SP, MM.

Besarnya potensi sumberdaya alam yang dimiliki Indonesia memungkinkan pengembangan subsektor peternakan sehingga menjadi sumber pertumbuhan baru perekonomian Indonesia. Salah satu komponen dari subsektor peternakan yang memiliki banyak manfaat dan berpotensi untuk dikembangkan di Indonesia adalah agribisnis sapi potong. Salah satu Kabupaten di Kalimantan Barat yang menjadi pengembangan program Inseminasi Buatan (IB) yaitu Kabupaten Ketapang. Populasi ternak sapi potong Kabupaten Ketapang Kecamatan Benua Kayong berjumlah 5074 ekor termasuk di dalamnya Kelurahan Tuan-Tuan yang memiliki potensi dalam penerapan program inseminasi buatan. Sehubungan dengan hal tersebut, penggunaan teknologi ternak dengan Inseminasi Buatan sangat membantu dalam peningkatan produktifitas ternak sapi potong

Penelitianini bertujuan untuk menganalisis persepsi peternak sapi potong terhadap inseminasi buatan, serta menganalisis hubungan antara karakteristik dengan persepsi peternak. Metodeanalisis yang digunakan dalam penelitian ini adalah metode survei dengan menggunakan skala likert dan Korelasi Rank Spearman dari karakteristik dengan persepsi peternak. Penentuan responden dilakukan secara acak sederhana dengan jumlah responden yang diambil sebanyak 33 orang peternak yang menggunakan IB. Data primer diperoleh melalui teknik wawancara berdasarkan kuisioner, dan data sekunder diperoleh dari kantor desa, kantor kecamatan dan instansi terkait.

Hasil penelitian menunjukkan bahwa : (1) persepsi peternak terhadap inseminasi buatan termasuk kategori baik $(87,88 \%)$; (2) terdapat hubungan yang cukup erat, signifikan dan searah antara umur dengan persepsi peternak terhadap inseminasi buatan dengan $r s=0,352$. Terdapat hubungan yang sangat lemah, tidak singnifikan dan searah antara pendidikan formal $(r s=0,099)$, pengalaman beternak $(r s=0,098)$ dengan persepsi peternak terhadap IB. sedangkan anggota keluarga memiliki hubungan yang sangat lemah, tidak signifikan dan tidak searah dengan persepsi peternak terhadap IB ( $\mathrm{rs}=-$ 0,157).
\end{abstract}

Kata kunci: Persepsi peternak, Inseminasi Buatan. 


\section{PENDAHULUAN}

Sehubungan dengan adanya program pemerintah yang berupa Rencana Pembangunan Lima Tahun yang dimulai tahun 1969, maka bidang peternakan pun ikut dibangun. Pada awal tahun 1973 pemerintah memasukan semen beku ke Indonesia. Dengan adanya semen beku inilah perkembangan Inseminasi Buatan mulai maju dengan pesat, sehingga hampir menjangkau seluruh provinsi di Indonesia salah satunya Kalimantan Barat Kabupaten Ketapang.

Sejauh ini upaya pemerintah Kabupaten Ketapang dalam mengembangkan program Inseminasi Buatan sangat menentukan, khususnya peranan penyuluhan dalam berbagai kegiatan. Berdasarkan hasil lapangan diketahui bahwa beberapa titik kelemahan dari kegiatan penyuluhan menyebabkan penyuluhan yang salah sasaran dan kerugian dalam peningkatan produktifitas. Keberhasilan Program Inseminasi Buatan (IB) banyak diterntukan oleh perilaku peternak, karena intensitas menggunakan inseminasi buatan dipengaruhi oleh karakteristik seseorang.

Kelurahan Tuan-tuan, Kecamatan Benua Kayong sebagian masyarakatnya mempunyai usaha pemeliharaan ternak sapi potong. Faktor penghambat yang diduga sebagai penyebab rendahnya produktivitas ternak di Kelurahan Tuan-tuan yaitu manajemen pemeliharaan yang belum optimal, usaha sampingan, system pemuliaan dan seleksi bibit yang tidak terarah, dan rendahnya produktifita sapi akibat jarak beranak.

Masyarakat Kelurahan Tuan-tuan Kecamatan Benua Kayong Kabupaten Ketapang walaupun merupakan masyarakat yang relatif homogen sebagai masyarakat agraris, tetapi secara individual memiliki karakteristik yang berlainan, sehingga persepsi dan penerimaan peternak juga diduga akan berbeda satu sama lain. Keyakinan terhadap manfaat Inseminasi Buatan di kalangan peternak sapi potong di Kelurahan Tuan-tuan Kecamatan Benua Kayong Kabupaten Ketapang yang tidak merata dapat menyebabkan kurang berhasilnya kinerja Inseminasi Buatan di wilayah tersebut. Untuk itu tujuan dari penelitian ini adalah untuk mengetahui: (1) bagaimana persepsi peternak sapi potong terhadap inseminasi buatan; (2) sejauh mana hubungan antara karakteristik peternak dengan persepsi peternak terhadap inovasiin seminasi buatan di daerah penelitian.

\section{METODE PENELITIAN}

Metodedan Lokasi Penelitian Metode penelitian yang digunakan adalah metode deskriptif dengan metode survey. Lokasi penelitian ditentukan secara sengaja (Purposive) di Kelurahan Tuan-tuan Kecamatan Benua Kayong Kabupaten Ketapang, dengan dasar pertimbangan bahwa sebagian besar Kelurahan Tuan-tuan merupakan salah satu daerah yang masyarakatnya menjalankan usaha peternakan sapi potong dan penerapan Inseminasi Buatan.

\section{Populasidan Teknik Pengambilan Sampel}

Pengambilan data primer didilakukan melalui wawancara yang berpedoman pada kuisioner yang telah disiapkan serta melakukan observasi sebagai tambahan informasi. Penentuan responden dilakukan dengan cara Simpel Random Sampling sebanyak 33 orang dari populasi peternak sapi potong di desa tersebut sebanyak 222 orang (Dinas Pertaninan dan Peternakan, 2010)

Variabel dalam penelitian ini adalah persepsi peternak terhadap inseminasi buatan, yang diukur melalui sub variable : (1) tingkat pengetahuan peternak mengenai inseminasi buatan; (2) minat peternak terhadap inseminsi buatan; (3) penilaian peternak terhadap inseminasi buatan. Sementara variable karakteristik peternak yang diukur 
melalui sub variabel : (1) umur; (2) tingkat pendidikan; (3) pengalaman beternak; (4) jumlah anggota keluarga; (5) kepemilikan ternak (AlimdanNurlina, 2004)

\section{Analisis Data}

Analisis persepsi peternak terhadap IB diuji dengan menggunakan skala likert (Silalahi, 2009). Analisis statistik yang digunakan untuk mengetahui hubungan karakteristik dengan persepsi IB adalah uji Rank Spearman (Somantri dan Syahbana, 2006). Keeratan hubungan antara karakteristik peternak dengan persepsi peternak mengenai inseminasi buatan diukur dengan menggunakan tabel nilai koefisien korelasi (Agritama, 2012).

\section{HASIL DAN PEMBAHASAN}

\section{Persepsi Peternak sapi Potong Terhadap Inseminasi Buatan (IB)}

Persepsi peternak terhadap inseminasi buatan merupakan tanggapan para peternak sapi potong terhadap inseminasi buatan, yang dilihat dari tingkat pengetahuan peternak, penilaian peternak dan minat peternak sapi potong terhadap manfaat inseminasi buatan sebagai suatu inovasi bagi mereka. Persepsi peternak terhadap inseminasi buatan dapat dilihat pada tabel 1 .

\section{Persepsi Peternak Berdasarkan Pengetahuan Terhadap Inseminasi Buatan}

Berdasarkan tabel 1 nampak bahwa sebagian besar peternak responden (87,88\%) mempersepsikan inseminasi buatan dengan baik, sementara sebagian peternak lainnya mempersepsikan kurang baik. Pengetahuan peternak yang tergolong baik, disebabkan karena peternak sering mendengar tentang IB baik dari peternak lain maupun dari penyuluhdan inseminator yang melakukan kegiatan penyuluhan yang diadakan sebulan sekali.

Tabel 1. Distribusi Persepsi Peternak Terhadap Inseminasi Buatan

\begin{tabular}{llccc}
\hline \multirow{2}{*}{ No. } & \multicolumn{2}{c}{ Uraian } & \multicolumn{3}{c}{ Kategori } \\
\cline { 3 - 5 } & & Baik & Kurang baik & Tidak baik \\
\hline 1. & Pengetahuan terhadap & $84,84 \%$ & $15,15 \%$ & 0 \\
2. & Minat terhadap IB & $90,90 \%$ & $9,09 \%$ & 0 \\
3. & Penilaian terhadap IB & $93,93 \%$ & $6,06 \%$ & 0 \\
\hline & PersepsiPeternak & $\mathbf{8 7 , 8 8 \%}$ & $\mathbf{1 2 , 1 2 \%}$ & $\mathbf{0}$ \\
\hline
\end{tabular}

Sumber : Analisis Data Primer, 2012.

\section{Persepsi Peternak Berdasarkan PenilaianTerhadap Inseminasi Buatan}

Pada tabel 2 terlihat bahwa penilaian peternak responden terhadap inseminasi buatan adalah baik sebesar(90,90\%). Penilaian peternak terhadap IB dikaji melalui ciri-ciri inovasi sebagai berikut, penilaian baik $(96,96 \%)$ peternak terhadap keuntungan relatif dari inseminasi buatan karena peternak telah melihat hasil ternak IB mempunyai kenaikan berat badan yang cepat dibandingkan dengan ternak sapi lokal. Hal ini sesuai dengan pendapat (Ismaya, 1999) bahwa dengan menggunakan IB, peternak mendapatkan bibit yang unggul serta memperoleh keturunan yang cepat besar disamping tinggi produksinya. 
Kompatabilitas yaitu sejauh mana inovasi inseminasi buatan konsisten dengan kebutuhan peternak. Sebagian besar responden (84,84\%) menyatakan bahwa menggunakan inseminasi buatan lebih mudah dari pada menggunakan penjantan/kawin alami, namun sebagian kecil merasa khawatirakan resiko kematian induk pada saat melahirkan karena anak yang dilahirkan relatif lebih besar.

Dalam hal kompleksitas atau tingkat kerumitan menggunakan IB, sebagian besar responden $(63,63 \%)$ menilai mudah, dikarenakan inseminator IB setempat memberikan arahan mengenai IB kepada peternak tentang bagaimana mempercepat deteksi birahi dengan pemberian hormon seperti ovolumon kepada ternak sapi selain itu untuk mempermudah pelaksanaan IB dianjurkannya penyediaan kandang jepit untuk kemudahan dalam melakukan pemeriksaan dan pemberian obat pada ternak sapi sehingga waktu dalam pelaksanaan inseminasi buatan menjadi lebih efisien.

Penilain sebagian responden $(57,57 \%)$ pada kategori baik terhadap triabilitas (intentitas penggunaan IB) disebabkan karena peternak dapat mencoba 1 atau 2 kali IB pada ternaknya, dan apabila gagal inseminator akan tetap melakukan inseminasi pada ternak tanpa biaya tambahan atau gratis sampai inseminasi buatan pada ternak berhasil.

Nilai observabilitas sebesar $(96,96 \%)$ untuk kategori baik, disebabkan karena peternak telah melihat bahwa ternak hasil inseminasi buatan memiliki bobot badan yang lebih besar tinggi dan dipercaya merupakan bibit sapi potong unggul dengan kualitas ternak yang baik sehingga diharapkan daya jualnya lebih tinggi.

Tabel 2. Distribusi Persepsi Peternak Terhadap Inseminasi Buatan

\begin{tabular}{|c|c|c|c|c|}
\hline \multirow{2}{*}{ No. } & \multirow{2}{*}{ Uraian } & \multicolumn{3}{|c|}{ Kategori } \\
\hline & & Baik & Kurang baik & Tidak baik \\
\hline 1. & $\begin{array}{l}\text { Pengetahuan terhadap } \\
\text { IB }\end{array}$ & $84,84 \%$ & $15,15 \%$ & 0 \\
\hline 2. & Minat terhadap IB & $90,90 \%$ & $9,09 \%$ & 0 \\
\hline 3. & Penilaian terhadap IB & $93,93 \%$ & $6,06 \%$ & 0 \\
\hline & PersepsiPeternak & $87,88 \%$ & $12,12 \%$ & 0 \\
\hline
\end{tabular}

Sumber : Analisis Data Primer, 2012.

\section{Persepsi Peternak Berdasarkan Minat Terhadap Inseminasi Buatan}

Persepsi peternak berdasarkan minat terhadap IB tergolong baik (90,90\%) disebabkan karena seringnya peternakb erkonsultasi dengan penyuluh maupun dengan peternak lain yang sudah mencoba inseminasi buatan.

Tabel 3. Distribusi Persepsi Peternak berdasarkan Penilaian terhadap Inseminasi Buatan

\begin{tabular}{|c|c|c|c|c|c|c|c|c|}
\hline \multirow{3}{*}{$\begin{array}{l}\text { Penilaian Peternak } \\
\text { Kenaikan berat } \\
\text { badan ternak IB } \\
\text { KonsistensilB }\end{array}$} & \multicolumn{8}{|c|}{ Persepsi Peternak Inseminasi Buatan } \\
\hline & \multicolumn{2}{|c|}{ Baik } & \multicolumn{2}{|c|}{ Kurang Baik } & \multicolumn{2}{|c|}{ Tidak Baik } & \multicolumn{2}{|c|}{ Jumlah } \\
\hline & 32 & $96,96 \%$ & 0 & 0 & 1 & $3,03 \%$ & 33 & $100 \%$ \\
\hline $\begin{array}{l}\text { KonsistensilB } \\
\text { dengan kebutuhan } \\
\text { ternak }\end{array}$ & 28 & & 5 & & 0 & 0 & 33 & \\
\hline Kerumitan IB & 21 & $63,63 \%$ & 10 & $30,30 \%$ & & $6,06 \%$ & & $100 \%$ \\
\hline Intensitas & 1 & 7 & 10 & 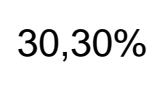 & 4 & $12,12 \%$ & 33 & 1 \\
\hline Kualitas ternak IB & 2 & $96,96 \%$ & 1 & $3,03 \%$ & 0 & 0 & 33 & $100 \%$ \\
\hline
\end{tabular}

Sumber : Analisis Data Primer, 2012. 


\section{Hubungan Antara Karakteristik Peternak Dengan Persepsi Peternak Terhadap Inseminasi Buatan Pada Sapi Potong}

Untuk mengetahui hubungan antara karakteristik peternak dengan persepsi peternak dapat dilihat pada tabel 4 . Hasil perhitungan seperti pada tabel 4 menunjukkan bahwa hubungan peternak dengan persepsinya terhadap inseminasi buatan pada sapi potong lebih berhubungan cukup erat dengan umur dan kepemilikan ternak, sementara pendidikan formal, pengalaman beternak hubungannya sangat lemah karena nilai rs kurangdari 0,20. Nilai korelasi Rank Spearman yang negatif untuk jumlah anggota keluarga menunjukkan bahwa banyaknya jumlah anggota keluarga tidak menunjukkan adanya pengaruh bagi peternak dalam pengambilan keputusan menggunakan IB, akan tetapi lebih pada kemudahan dalam pemeliharaan ternak.

Tabel 4. Hubungan antara karakteristik dengan persepsi peternak terhadap Inseminasi Buatan pada sapi potong

\begin{tabular}{|c|c|c|c|}
\hline \multirow{3}{*}{ Karakteristik } & \multicolumn{3}{|c|}{ Koefisien Korelasi Rank Spearman } \\
\hline & \multicolumn{3}{|c|}{ Persepsi Peternak Terhadap Inseminasi Buatan } \\
\hline & $\begin{array}{l}\text { Nilai Korelasi Rank } \\
\text { Spearman (rs) }\end{array}$ & Sig & $\begin{array}{l}\text { Interpretasi Tingkat } \\
\text { Hubungan (Guilford) }\end{array}$ \\
\hline Umur & 0,352 & 0,044 & Cukup Erat \\
\hline Pendidikan Formal & 0,099 & 0,584 & Sangat Lemah \\
\hline Jumlah anggota keluarga & $-0,157$ & 0,383 & Sangat Lemah \\
\hline Pengalaman Beternak & 0,098 & 0,588 & Sangat Lemah \\
\hline Kepemilikan Ternak & 0,313 & 0,076 & Cukup Erat \\
\hline Karakteristik & 0,227 & 0,204 & CukupErat \\
\hline
\end{tabular}

Sumber : Analisi Data Primer, 2013

\section{KESIMPULAN DAN SARAN}

\section{Kesimpulan}

Persepsi peternak di Kelurahan Tuan-Tuan Kecamatan Benua Kayong Kabupaten Ketapang adalah baik $(87,88 \%)$ terhadap inseminasi buatan, hal tersebut dapat dilihat dari persepsi peternak yang dilihat dari tingkat pengetahunan peternak terhadap inseminasi buatan $(84,84 \%)$ baik, persepsi peternak yang dilihat dari penilaian terhadap inseminasi buatan $(93,93 \%)$ baik danpersepsi peternak yang dilihat dari minat peternak terhadap inseminsi buatan $(90,90 \%)$ baik.

Terdapat hubungan yang cukuperat, signifikan dan searah antara antara umur (rs $=0,352)$ dan kepemilikan ternak $(r s=0,313)$ dengan persepsi peternak terhadap IB. Terdapat hubungan yang sangat lemah tidak signifikan dan searah antara pendidikan formal $(r s=0,099)$ dan pengalaman beternak ( $r s=0,098)$ dengan persepsi peternak terhadap IB. Terdapat hubungan yang sangat lemah, tidak signifikan dan tidak searah antara anggota keluarga dengan persepsi peternak terhadap IB dengan nilai $r s=-0,157$.

\section{Saran}

1. Diperlukan kegiatan penyuluhan yang lebih efektif tentang teknis dalam mendeteksi waktu birahi sapi yang tepat. 
2. Perlu adanya pembuatan kandang jepit yang diarahkan diberbagai tempat yang dekat dengan kandang sapi.

3. Perlu adanya ketersediaan semen beku secara berkelanjutan untuk IB supaya peternak tidak kembali mengawinkan sapinya secara lokal.

4. Adanya kemudahan komunikasi antara peternak dengan petugas IB agar tingkat keberhasilan inseminasi pada sapi menjadi lebih tepat waktu.

\section{DAFTAR PUSTAKA}

Agritama, Surya. 2012. Persepsi Prtani Terhadap Budidaya Padi System Of Rice Intensification (SRI) di Desa Ringgit Kecamatan Ngombol Kabupaten Purwokerto. Jurnal Volume 1 Nomor 2. Program Studi Agribisnis Fakultas Pertanian Universitas Muhammadiyah Purworejo.

Alim, Syahirul dan Nurlina, Lilis. 2007. Hubungan Antara Karakteristik Dengan Persepsi Peternak Sapi Potong Terhadap Inseminasi Buatan.Skripsi. Fakultas Peternakan Universitas Padjadjaran

Dinas Pertanian dan Peternakan. Evaluasi Kinerja Program IB Tahun 2008-2009 dan Rencana Kegiatan IB Tahun 2010 Kabupaten Ketapang.

Ismaya, 1999. Kawin Buatan pada Sapi dan Kerbau. Fakultas Peternakan Universitas Gadjah Mada.Yogyakarta.

Silalahi, Ulber. 2009. Metode Penelitian Sosial. PT Refika Aditama, Bandung

Somantri, Ating dan Muhidin, Ali. 2006. Statistika Dalam Penelitian. Pustaka Setia, Bandung. 